\title{
Severidade de antracnose em folhas de sorgo submetido a doses crescentes de silício ${ }^{1}$
}

\author{
Severity of anthracnose in sorghum leaves subjected to increasing levels of silicon
}

\author{
Gil Rodrigues Santos ${ }^{2 *}$, Artenisa Cerqueira Rodrigues ${ }^{3}$, Aurenivia Bonifacio ${ }^{4}$, Aloísio Freitas Chagas Junior e $^{5}$ \\ Paulo Henrique Tschoeke ${ }^{6}$
}

\begin{abstract}
RESUMO - A antracnose foliar é causada pelo fungo Colletotrichum sublineolum Hann. Kabát et Bub. (sin. C. graminicola (Ces.) G.W. Wils.) em plantas de sorgo podendo reduzir a produtividade de grãos e forragem, e o manejo adequado da nutrição mineral desta planta pode se apresentar como um mecanismo de controle sobre a antracnose. Dentre os minerais utilizados para o manejo de doenças, o silício destaca-se por reduzir a severidade das doenças em várias culturas. Diante do exposto, este trabalho teve por objetivo avaliar a severidade da antracnose em diferentes genótipos de sorgo suplementados com doses crescentes de silício. Para tal, realizaram-se experimentos em condições de casa de vegetação e de campo onde os genótipos de sorgo DOW 1F305 e A9735R foram suplementados com doses crescentes de silício $\left(0 ; 500 ; 1.000 ; 1.500 ; 2.000 ; \mathrm{e} 4.000 \mathrm{~kg} \mathrm{ha}^{-1}\right) \mathrm{e}$ avaliados quanto à severidade da antracnose. Avaliou-se a severidade da doença por meio de uma escala de notas e, em seguida, amostras foram coletadas para determinação da concentração de silício nas folhas. Após a análise dos resultados, concluiu-se que houve redução na severidade da antracnose em resposta a adubação com silício para ambos os genótipos avaliados. Apesar do genótipo de sorgo DOW 1F305 acumular menores teores de silício em suas folhas, este genótipo foi mais resistente ao ataque da antracnose foliar.
\end{abstract}

Palavras-chave: Colletotrichum sublineolum. Sorghum bicolor. Silicato de cálcio e magnésio.

\begin{abstract}
Anthracnose in the leaves of sorghum plants is caused by the fungus Colletotrichum sublineolum Hann. Kabát et Bub. (syn. C. graminicola (Ces.) GW Wils.), and is responsible for reducing the yield of grain and forage. The proper management of the mineral nutrition of the plant may be a mechanism for the control of anthracnose. Among the minerals used in disease management, silicon stands out for reducing the severity of the disease in various crops. Given the above, this study aimed to assess the severity of anthracnose in different sorghum genotypes when supplemented with increasing levels of silicon. To this end, experiments were carried out under both greenhouse and field conditions, where the sorghum genotypes DOW 1F305 and A9735R were supplemented with increasing levels of silicon $\left(0,500,1000,1500,2000\right.$, and $\left.4000 \mathrm{~kg} \mathrm{ha}^{-1}\right)$ and assessed for the severity of anthracnose. We evaluated the severity of the disease with a rating scale and then samples were collected for determination of the concentration of silicon in the leaves. After analyzing the results, it was concluded that there was a reduction in the severity of anthracnose in response to fertilization with silicon in both of the evaluated genotypes. Although genotype DOW 1F305 accumulated lower silicon levels in the leaves, it was more resistant to foliar anthracnose.
\end{abstract}

Key words: Colletotrichum sublineolum. Sorghum bicolor. Calcium and magnesium silicate.

\footnotetext{
*Autor para correspondência

Recebido para publicação em 18/10/2012; aprovado em 09/12/2013

Parte de uma Dissertação de Mestrado

${ }^{2}$ Departamento de Agronomia, Laboratório de Fitopatologia, Universidade Federal do Tocantins, Campus Universitário de Gurupi, Caixa Postal 66, Gurupi-TO, Brasil, 77.402-970, gilrsan@uft.edu.br

${ }^{3}$ Departamento de Engenharia Agrícola e Solos, Universidade Federal do Piauí, Campus Universitário Ministro Petrônio Portella, Teresina-PI, Brasil. artenisacerqueira@hotmail.com

${ }^{4}$ Departamento de Ciências Agrárias e Tecnológicas, Universidade Federal do Tocantins, Campus Universitário de Gurupi, Gurupi-TO, Brasil. bonifacio.a@live.com

${ }^{5}$ Departamento de Agronomia, Laboratório de Microbiologia, Universidade Federal do Tocantins, Campus Universitário de Gurupi, Gurupi-TO, Brasil.chagasjraf@uft.edu.br

${ }^{6}$ Programa de Pós-Graduação em Produção Vegetal, Universidade Federal do Tocantins, Campus Universitário de Gurupi, Gurupi-TO, Brasil. pht@uft.edu.br
} 


\section{INTRODUÇÃO}

A antracnose, causada pelo fungo Colletotrichum sublineolum Hann. Kabát et Bub. (syn. C. graminicola (Ces.) G.W. Wils.), é considerada a mais importante das doenças que afetam o sorgo (SUKNO et al., 2008). A antracnose nas folhas do sorgo pode reduzir a produtividade de grãos e forragem em 50\%, ou mais, a depender do grau de severidade (COSTA et al., 2008; NGUGI et al., 2000). A doença encontra-se amplamente disseminada pelas principais regiões produtoras no país e entre as medidas de controle destacam-se o uso de sementes certificadas, a rotação de culturas, controle químico e genótipos geneticamente resistentes (ZANETTE et al., 2009). Além disso, o manejo nutricional pode ser uma importante ferramenta na melhoria da barreira fisiológica que pode controlar inúmeras doenças, dentre elas a antracnose (TANAKA et al., 2008).

O silício, dentre os minerais utilizados para o manejo sanitário das plantas cultivadas, pode reduzir a severidade de doenças em algumas culturas (EPSTEIN, 1999; SANTOS et al., 2011). Foram registradas interações significativas entre as variedades de cafeeiro infectadas por Cercospora coffeicola e a presença de silício na redução da intensidade da infecção fúngica devido a ação fungistática proporcionada pelo silício (POZZA et al., 2004). A adubação do solo com suplementação de silicato de potássio foi eficiente em reduzir a incidência e severidade da ferrugem causada por Hemileia vastatrix em plantas de cafeeiro (NOJOSA, 2003) e no combate à infecção de Fusarium semitectum em sementes de soja (JULIATTI et al., 2004). Plantas de feijoeiro suplementadas com silicato de cálcio exibiram redução na antracnose causada por Colletotrichum lindemuthianum (MORAES et al., 2006).

O silício é um elemento mineral com efeito pronunciado em plantas expostas a condições estressantes, como o estresse hídrico e ataque de patógenos, podendo ativar mecanismos físicos e bioquímicos de defesa (GOUSSAIN et al., 2002; MA; YAMAJI, 2008; PULZ et al., 2008; SANTOS et al., 2010). Espécies exclusoras de silício podem acumular o silício nas raízes ao invés de translocá-lo para a parte aérea, fato que já foi observado em algumas espécies de soja (GROTHGE-LIMA, 1998) e em plantas de feijão (MA et al., 2001) suplementadas com silício. Uma vez que o silício é acumulado nas raízes, este não é realocado para as folhas e seus efeitos benéficos de proteção, tal como a silicificação das células foliares, não ocorrem e deixam a planta susceptível ao ataque de patógenos (CURRIE; PERRY, 2007; KIM et al., 2002).

Diante do exposto, este trabalho teve por objetivo avaliar a severidade da antracnose causada pelo fungo C. sublineolum em diferentes genótipos de sorgo suplementados com doses crescentes de silício.

\section{MATERIAL E MÉTODOS}

\section{Caracterização da área experimental}

O experimento foi realizado em condições de casa de vegetação e campo, ambos no campo experimental da Universidade Federal do Tocantins (UFT) localizado no município de Gurupi (TO). O solo do campo experimental foi classificado como sendo um Latossolo Vermelho Amarelo Distrófico (Tabela 1). No período de condução dos experimentos foi registrada temperatura do ar média de $26{ }^{\circ} \mathrm{C}$; umidade relativa do ar média de $82 \%$ e precipitação pluviométrica média de 195,2 mm.

\section{Instalação e condução do experimento em casa de vegetação}

Para o experimento em casa de vegetação, foram semeadas quatro sementes de cada genótipo de sorgo, DOW 1F305 e A9735R, em vasos contendo como substrato $6,0 \mathrm{~kg}$ de solo coletados no campo experimental e esterco bovino, na proporção de 1:1. O substrato foi mantido úmido com irrigações diárias $(1,0 \mathrm{~L}$ vaso $^{-1}$ ) e suplementado com nitrogênio (40 kg de ureia ha ${ }^{-1}$ ) seguindo recomendações após a análise química do solo (Tabela 1). A instalação dos tratamentos foi realizada na ocasião da semeadura após a adubação com silício do produto Yoorin Master- ${ }^{\circledR}$ (Tabela 2 ) nas doses de 7,5; 15,$0 ; 22,5 ; 30,0 ;$ e $60,0 \mathrm{~g}_{\text {vaso }}{ }^{-1}$ que corresponderam a 500 ; $1.000 ; 1.500 ; 2.000$; e $4.000 \mathrm{~kg} \mathrm{ha}^{-1}$. Utilizou-se um vaso com solo não adubado com silício como controle. Dez dias após a semeadura, foi realizado o desbaste mantendo-se duas plantas por vaso.

Para a inoculação com C. sublineolum, agente causal da antracnose, o fungo foi previamente isolado de plantas de sorgo apresentando sintomas da doença e crescido em placa de Petri contendo meio BDA. Para o preparo do inoculo, adicionou-se $15,0 \mathrm{~mL}$ de água destilada esterilizada em cada placa de Petri e, posteriormente, realizou-se uma fricção na superfície do meio com pincel de cerdas macias para liberação dos conídios. Os conídios foram quantificados utilizando-se a câmara de Neubauer e a solução de inoculo foi preparada na concentração de 1,0 x $10^{5}$ conídios $\mathrm{mL}^{-1}$. Posteriormente, $15,0 \mathrm{~mL}$ da solução do inoculo foi borrifada nas folhas das plantas em duas épocas distintas: 30 e 60 dias após o plantio.

A avaliação da severidade da antracnose nos genótipos foi iniciada 10 dias após a inoculação e mensurada utilizando a escala de notas adaptada por Santos et al. (2005), onde: 0 - planta sadia; 1 - menos de $1 \%$ da área foliar afetada; 3 - entre 1 e $5 \%$ da área foliar afetada; 5 - entre 6 e 25\% da área foliar afetada; 7 entre 26 a $50 \%$ da folha afetada; 9 - mais que $50 \%$ da área foliar afetada. As notas foram convertidas para 
Tabela 1 - Caracterização química $(0-20 \mathrm{~cm})$ do solo utilizado nos experimentos

\begin{tabular}{|c|c|c|c|c|c|c|c|c|c|c|}
\hline & \multirow{2}{*}{$\mathrm{pH}$} & $\mathrm{P}$ & $\mathrm{K}$ & $\mathrm{Ca}$ & $\mathrm{Mg}$ & $\mathrm{H}+\mathrm{Al}$ & MO* & Areia & Silte & Argila \\
\hline & & \multicolumn{2}{|c|}{$\mathrm{mg} \mathrm{dm}^{-3}$} & \multicolumn{3}{|c|}{$\mathrm{cmol} \mathrm{dm}^{-3}$} & \multicolumn{4}{|c|}{$\%$} \\
\hline Solo & 5,7 & 3,7 & 27,1 & 1,72 & 0,53 & 2,90 & 3,69 & 69,50 & 4,77 & 25,76 \\
\hline
\end{tabular}

Tabela 2 - Composição química do Yoorin Master- $1^{\circledR}$ utilizado para adubação nas doses de silício

\begin{tabular}{cccccccccc}
\hline & $\mathrm{P}_{2} \mathrm{O}_{5}$ & $\mathrm{Ca}$ & $\mathrm{Mg}$ & $\mathrm{B}$ & $\mathrm{Cu}$ & $\mathrm{Mn}$ & $\mathrm{Si}$ & $\mathrm{Zn}$ \\
\cline { 2 - 9 } & 17,50 & 18,00 & 7,00 & 0,10 & 0,05 & 0,15 & 10,00 & 0,55 \\
\hline
\end{tabular}

${ }^{* *}$ Percentual total. Fonte: Fabricante Mitsui \& Co. S.A

porcentagem de área foliar infectada pelo ponto médio de cada nota para obtenção das curvas de progresso da doença em cada tratamento.

\section{Semeio e condução do experimento em campo}

Para o plantio das sementes dos genótipos de sorgo DOW 1F305 e A9735R, foram abertos sulcos com arado subsolador e realizou-se uma adubação de base com NPK (5-25-15; $\left.400 \mathrm{~kg} \mathrm{ha}^{-1}+0,3 \% \mathrm{Zn}\right)$, conforme metodologia usual na região. O semeio foi realizado distribuindo-se oito sementes de sorgo por metro linear e, após o desbaste, mantiveram-se cinco plantas por metro linear. A parcela experimental constituiu-se de fileiras espaçadas de $0,7 \mathrm{~m}$ de largura por 6,0 m de comprimento. A aplicação de silício foi realizada na ocasião da semeadura utilizando o produto Yoorin Master- $1^{\circledR}$ (Tabela 1) nas seguintes doses: 0 (controle); $500 ; 1.000 ; 1.500 ; 2.000 ;$ e $4.000 \mathrm{~kg} \mathrm{ha}^{-1}$. Como tratos culturais, foram realizadas capina manual para o controle das plantas daninhas e duas pulverizações com o inseticida Permetrina (Pounce $384 \mathrm{CE} ; 150 \mathrm{~mL} \mathrm{ha}^{-1}$ ) para controlar a Lagarta do cartucho. Durante o período experimental não foi realizada aplicação de fungicidas.

A avaliação da severidade da antracnose teve início por ocasião da emissão das panículas, com intervalo de sete dias, até o ponto de colheita. Utilizou-se a escala de notas de Santos et al. (2005) para avaliação da doença e as notas foram convertidas para porcentagem de área foliar infectada. Amostras foliares foram coletadas e encaminhadas ao Laboratório de Fertilidade do Solo da Universidade Federal de Uberlândia para quantificação do silício pelo método de Korndörfer et al. (2004).

\section{Delineamento experimental e análise estatística}

O delineamento utilizado em ambas as condições experimental (casa de vegetação e campo) foi blocos ao acaso com esquema fatorial de 2 × 6 , sendo dois genótipos de sorgo (DOW 1F305 e A9735R) e seis níveis de silício $\left(0 ; 500 ; 1.000 ; 1.500 ; 2.000 ;\right.$ e $\left.4.000 \mathrm{~kg} \mathrm{ha}^{-1}\right)$, com quatro repetições. Os resultados obtidos foram submetidos à análise de variância (ANOVA) em esquema fatorial (Teste F; $P<0,05)$. Quando o teste $\mathrm{F}$ foi significativo, realizou-se o teste de Scott-Knott $(P<0,05)$ para os genótipos e análise de regressão para avaliar o efeito da aplicação das diferentes doses de silício. As análises supracitadas foram realizadas utilizando o programa estatístico SISVAR (FERREIRA, 2008).

\section{RESULTADOS E DISCUSSÃO}

\section{Severidade da antracnose em sorgo cultivado em casa de vegetação}

Os genótipos de sorgo DOW 1F305 e A9735R foram avaliados em condições de casa de vegetação quanto à severidade da antracnose em resposta às doses de silício (Tabela 3). De modo geral, as plantas de ambos os genótipos de sorgo suplementadas com diferentes doses de silício e inoculados com o fungo causador da antracnose aos 30 dias após o plantio (DAP) apresentaram menor severidade da antracnose foliar que as plantas inoculadas aos 60 DAP (Tabela 3). Heckman et al. (2003) observaram que ao suplementar plantas de abóbora com $\mathrm{CaSiO}_{3}$ houve maior resistência à antracnose e menor área abaixo da curva de progresso da doença (AACPD) em comparação com plantas não suplementadas com silício.

No presente estudo, houve diferentes padrões de resposta dos genótipos de sorgo avaliados em resposta aos níveis de silício e aos tempos de inoculação. O genótipo DOW 1F305apresentou menor severidade da antracnose em resposta às doses de silício aplicadas, independente do período de inoculação (Tabela 3). Houve redução de aproximadamente 
Tabela 3 - Percentual de área foliar afetada (\%) pela antracnose em genótipos de sorgo DOW 1F305 e A9735R inoculados 30 ou 60 dias após o plantio (DAP) e cultivados em condições de casa de vegetação

\begin{tabular}{|c|c|c|c|c|c|c|c|c|}
\hline \multirow{2}{*}{$\frac{\text { Genótipos }}{\text { DOW 1F305 }}$} & \multicolumn{6}{|c|}{ Doses de silício $\left(\mathrm{kg} \mathrm{ha}^{-1}\right)$} & \multirow{2}{*}{$\mathrm{Si}^{1}$} & \multirow{2}{*}{$\mathrm{R}^{2}$} \\
\hline & 0 & 500 & 1.000 & 1.500 & 2.000 & 4.000 & & \\
\hline $30 \mathrm{DAP}$ & $35,3 \mathrm{~b}$ & $12,6 \mathrm{~b}$ & $10,8 \mathrm{~b}$ & $8,6 \mathrm{~b}$ & $8,6 \mathrm{~b}$ & $8,6 \mathrm{~b}$ & LIN & $0,79 \mathrm{~ns}$ \\
\hline $60 \mathrm{DAP}$ & $45,5 \mathrm{a}$ & $26,4 \mathrm{a}$ & $16,3 \mathrm{a}$ & $22,8 \mathrm{a}$ & $22,8 \mathrm{a}$ & $22,8 \mathrm{a}$ & LIN & $0,67 \mathrm{~ns}$ \\
\hline \multicolumn{9}{|l|}{ A9735R } \\
\hline 30 DAP & $47,6 \mathrm{a}$ & $31,2 \mathrm{~b}$ & $33,2 \mathrm{~b}$ & $28,0 \mathrm{a}$ & $14,0 \mathrm{~b}$ & $15,3 \mathrm{~b}$ & POL & $0,88^{* *}$ \\
\hline $60 \mathrm{DAP}$ & $50,5 \mathrm{a}$ & $47,2 \mathrm{a}$ & $42,5 \mathrm{a}$ & $25,8 \mathrm{a}$ & $17,8 \mathrm{a}$ & $17,3 \mathrm{a}$ & POL & $0,91 * *$ \\
\hline
\end{tabular}

Nas diferentes épocas de inoculação, médias seguidas pela mesma letra na coluna não diferem estatisticamente entre si pelo teste de Scott-Knott $(P<0,05)$. ${ }^{1}$ Tipo de ajuste da regressão para o silício $(\mathrm{Si}): \mathrm{LIN}=$ linear; $\mathrm{POL}=$ polinomial. $\mathrm{R}^{2}=$ *significativo a $1 \%$; **significativo a $5 \%$; ns = não significativo

$65 \%$ na severidade da antracnose no genótipo de sorgo DOW 1F305 suplementadas com $500 \mathrm{~kg} \mathrm{ha}^{-1}$ de silício em comparação com as plantas não suplementadas. Além disso, o genótipo de sorgo DOW 1F305 inoculado aos 30 DAP e suplementado com 1.500; 2.000; e $4.000 \mathrm{~kg} \mathrm{ha}^{-1}$ de silício apresentou respostas semelhantes quanto à severidade da antracnose (Tabela 3). Estes resultados indicam que a dose de $500 \mathrm{~kg} \mathrm{ha}^{-1}$ de silício já é suficiente para garantir uma defesa eficiente deste genótipo à antracnose.

De modo geral, o genótipo de sorgo A9735R apresentou maior susceptibilidade à antracnose que o genótipo DOW 1F305, independente da época de inoculação (Tabela 3). O genótipo de sorgo A9735R quando inoculado aos 30 DAP apresentou redução de 35\% na severidade da doença quando suplementadas com $500 \mathrm{~kg} \mathrm{ha}^{-1}$ de silício em comparação às plantas não suplementadas (Tabela 3). O genótipo de sorgo A9735R quando suplementado com silício e inoculado com a antracnose aos 60 DAP apresentou menor severidade da doença já quando suplementado com $1.000 \mathrm{~kg} \mathrm{ha}^{-1}$ de silício e a suplementação com $1.500 \mathrm{~kg} \mathrm{ha}^{-1}$ de silício foi responsável por reduzir a severidade em, aproximadamente, $50 \%$ (Tabela 3).

Os resultados apresentados no presente estudo evidenciam os efeitos positivos da suplementação com silício na redução na intensidade da antracnose. A intensidade da antracnose é menor em plantas que ainda não estão em fase reprodutiva (WANG et al., 2004), tal como observado no presente estudo. É provável que a exposição da planta ao patógeno numa fase mais inicial do desenvolvimento proporcione a formação de barreiras físicas que resultam em melhores respostas frente ao ataque de patógenos (CURRIE; PERRY, 2007; PULZ et al., 2008). Após ser absorvido, o silício induz a silicificação das células foliares formando uma barreira que proporciona proteção mecânica levando a uma diminuição da infecção por fitopatógenos (KIM et al., 2002). Além disso, pode ocorrer a indução na produção de fitoalexinas que agem como compostos de defesa vegetal (CAI et al., 2008; KORNDÖRFER, 2007; MA; YAMAJI, 2008; RODRIGUES et al., 2004).

\section{Severidade da antracnose em sorgo cultivado em condições de campo}

Observou-se que ambos os genótipos de sorgo estudados apresentaram decréscimo na severidade da antracnose foliar em resposta ao aumento na concentração de silício aplicado no solo (Figura 1). Solos intemperizados, arenosos e com alto potencial de lixiviação são favoráveis à aplicação de silício proporcionando respostas favoráveis das plantas à defesa contra o ataque de patógenos (MA et al., 2001; KORNDÖRFER, 2007; MA; YAMAJI, 2008). Quando os dois genótipos são comparados, é possível observar que o genótipo de sorgo DOW 1F305 mostrou forte correlação negativa $(R=-0.86)$ entre a severidade da antracnose foliar e o percentual de silício nas folhas (Figura 1A). Já o genótipo de sorgo A9735R apresentou correlação negativa $(R=-0,77)$ entre a severidade da antracnose foliar e o percentual de silício nas folhas, entretanto a regressão não foi significativa (Figura 2B).

A não indução de uma defesa contra patógenos frente à aplicação crescente de silício no solo pode estar relacionada, dentre várias causas, com uma carência de informações do quanto as cultivares exigem de silício para executar tal resposta de defesa (MAUAD et al., 2003). Além disso, estes resultados podem estar relacionados à baixa eficiência de absorção do silício por alguns genótipos de sorgo que podem apresentar incapacidade de extrair o silício do solo e incorporá-los nos limbos foliares, devido

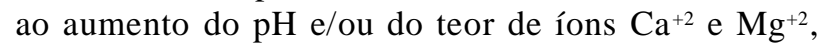
fornecidos pela prática da calagem antes da aplicação dos tratamentos (MA et al., 2001; BËLANGER et al., 2003; MA; YAMAJI, 2008; PULZ et al., 2008). 
Os genótipos de sorgo avaliados apresentaram diferenças quanto ao percentual de silício encontrado nas folhas. O genótipo de sorgo A9735R apresentou maior percentual de silício nas folhas em relação ao genótipo de sorgo DOW 1F305, entretanto foi mais susceptível ao ataque do fungo $C$. sublineolum, agente causal da antracnose (Tabela 4). De acordo com Ma et al. (2001), plantas acumuladoras são aquelas com teor de silício superior a $1 \%$, as intermediárias apresentam teor de silício variando de 0,5 a $1 \%$, enquanto as exclusoras apresentam concentração de silício na matéria seca inferior a $0,5 \%$. É provável que o silício acumulado pelo genótipo de sorgo A9735R tenha se acumulado em folhas mais velhas e assim as folhas novas apresentaramse mais susceptíveis ao ataque da antracnose, tal como sugerem Ngugi et al. (2000). Novos estudos deverão ser realizados para elucidar os mecanismos envolvidos na absorção de silício por genótipos de sorgo e, ainda, na busca de uma maior viabilidade do uso deste mineral no cultivo de sorgo em larga escala.

Figura 1 - Análise de regressão e correlação entre a severidade da antracnose e o percentual de silício nas folhas (\%) para os genótipos de sorgo DOW 1F305 (A) e A9735R (B)
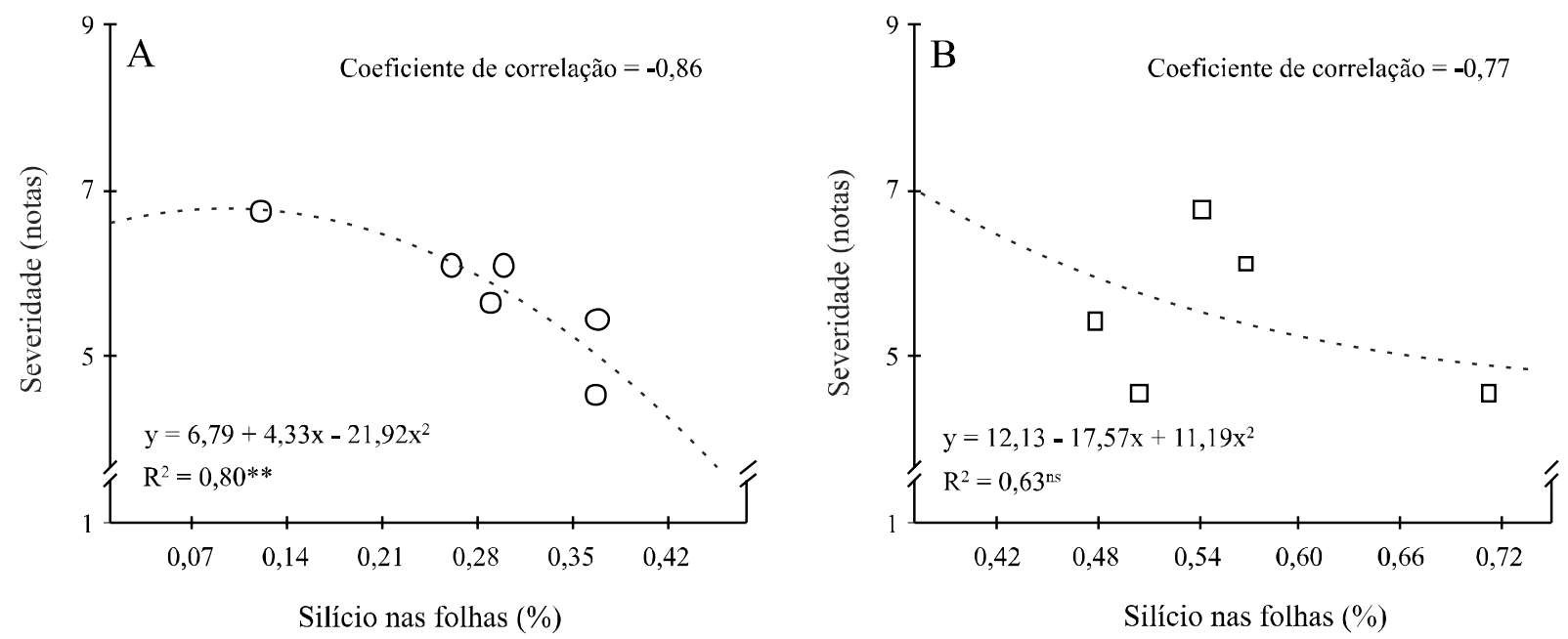

Curva da regressão com ajuste polinomial. $\mathrm{R}^{2}=*$ significativo a $1 \%$; * significativo a $5 \%$; $\mathrm{ns}=$ não significativo

Tabela 4 - Percentual de silício nas folhas dos genótipos de sorgo DOW 1F305 e A9735R em função das doses de silício aplicadas no solo

\begin{tabular}{lccccccccc}
\hline \multirow{2}{*}{ Genótipos } & \multicolumn{7}{c}{ Doses de silício $\left(\mathrm{kg} \mathrm{ha}^{-1}\right)$} & \multirow{2}{*}{$\mathrm{Si}^{1}$} & \multirow{2}{*}{$\mathrm{R}^{2}$} \\
\cline { 2 - 7 } & 0 & 500 & 1.000 & 1.500 & 2.000 & 4.000 & & $0,75^{*}$ \\
\hline DOW 1F305 & $0,12 \mathrm{~b}$ & $0,29 \mathrm{~b}$ & $0,30 \mathrm{~b}$ & $0,26 \mathrm{~b}$ & $0,37 \mathrm{~b}$ & $0,37 \mathrm{~b}$ & POL & $0,61^{* *}$ \\
\hline
\end{tabular}

Médias seguidas pela mesma letra na coluna não diferem estatisticamente entre si pelo teste de Scott-Knott $(P<0,05)$. ${ }^{1}$ Tipo de ajuste da regressão para o silício $(\mathrm{Si}): \mathrm{LIN}=$ linear; $\mathrm{POL}=$ polinomial. $\mathrm{R}^{2}=$ *significativo a $1 \%$; **ignificativo a $5 \%$; ns = não significativo

\section{CONCLUSÃO}

Houve diminuição na severidade da antracnose em resposta à suplementação com silício em ambos os genótipos de sorgo avaliados. Apesar do genótipo de sorgo DOW 1F305 acumular menores teores de silício em suas folhas, este foi mais resistente ao ataque da antracnose foliar.

\section{REFERÊNCIAS}

BÉLANGER, R. R.; BENHAMOU, N.; MENZIES, J. G. Cytological evidence of an active role of silicon in wheat resistance to powdery mildew (Blumeria graminis f. sp. tritici). Phytopathology, v. 93, n. 4, p. 402-412, 2003.

CAI, K. et al. Physiological and cytological mechanisms of silicon-induced resistance in rice against blast disease. Physiologia Plantarum, v. 134, p. 324-333, 2008. 
COSTA, R. V. et al. Controle genético da resistência do sorgo à antracnose foliar (Colletotrichum sublineolum). Sete Lagoas: Embrapa Milho e Sorgo, 2008. (Comunicado técnico 162).

CURRIE, H. A.; PERRY, C. C. Silica in plants: biological. biochemical and chemical studies. Annals of Botany, v. 100, n. 7, p. 1383-1389, 2007.

EMBRAPA (Empresa Brasileira de Pesquisa Agropecuária). Centro Nacional de Pesquisa de Solos. Sistema brasileiro de classificação de solos. $2^{\mathrm{a}}$ ed. Rio de Janeiro, 2006.

EPSTEIN, E. Silicon. Annual Review of Plant Physiology and Plant Molecular Biology, v. 50, p. 641-664, 1999.

FERREIRA, D. F. SISVAR: um programa para análises e ensino de estatística. Revista Symposium, v. 06, p. 36-41, 2008.

GOUSSAIN, M. M. et al. Efeito da aplicação de silício em plantas de milho no desenvolvimento biológico da Lagarta-do-Cartucho Spodoptera frugiperda (J.E. Smith) (Lepidoptera: Noctuidae). Neotropical Entomology, v. 31, n. 2, p. 305-310, 2002.

GROTHGE-LIMA, M. T. Interrelação cancro da haste (Diaporthe phaseolorum f. sp. meridionalis), nodulação (Bradyrhizobium japonicum) e silício em soja [Glycine max (L.) Merrill]. 1998. $58 \mathrm{f}$. Tese (Doutorado em Ciências). Centro de Energia Nuclear na Agricultura - Universidade de São Paulo, Piracicaba, 1998.

HECKMAN, J. R.; JOHNSTON, S.; COWGILL, W. Pumpkin yield and disease response to amending soil with silicon. HortScience, v. 38, p. 552-554, 2003.

JULIATTI, F. C.; et al.. Influência do silício na redução de podridão de sementes por Fusarium semitectum na cultura da soja. Bioscience Journal, v. 20, n. 2, p. 57-63, 2004.

KIM, S. G. et al. Silicon-induced cell wall fortification of rice leaves: a possible cellular mechanism of enhanced host resistance to blast. Phytopathology, v. 92, p. 1095-1103, 2002.

KORNDORFER, G. H.; PEREIRA, H. S.; CAMARGO, M. S. Análise de silício: solo, planta e fertilizante. Uberlândia, GPSiUFU, Boletim Técnico 2, 2004. 50 p.

KORNDÖRFER, G. H. Uso do Silício na agricultura. Informações agronômicas 117, 2007.

MA, J. F.; YAMAJI, N. Functions and transport of silicon in plants. Cellular and Molecular Life Sciences, v. 65, p. 3049-3057, 2008.

MA, J. F.; MIYAKE, Y.; TAKAHASHI, E. Silicon as a beneficial element for crop plants. In: DATNOFF, L. E.; SNYDER, G. H.; KORNDÖRFER, G. H., Eds., Silicon in agriculture, Studies in Plant Science 8, Amsterdam, Elsevier, 2001.p. 17-39.

MAUAD, M. et al. Teores de silício no solo e na planta de arroz de terras altas com diferentes doses de adubação silicatada e nitrogenada. Revista Brasileira de Ciência do Solo, v. 27, n. 5, p. 867-873, 2003.

MORAES, S. R. G. et al. Efeito de fontes de silício na incidência e na severidade da antracnose do feijoeiro. Fitopatologia Brasileira, v. 31, n. 1, p. 69-75, 2006.

NGUGI, H. K. et al. Epidemiology of sorghum anthracnose (Colletotrichum sublineolum) and leaf blight (Exserohilum turcicum) in Kenya. Plant Pathology, v. 49, p. 129-140, 2000.

NOJOSA, G. B. A. Efeito dos indutores na resistência de Coffea arabica L. à Hemileia vastatrix Berk \& Br. e Phoma costarricensis Echandi. 2003. 102 f. Tese (Doutorado em Fitopatologia). Universidade Federal de Lavras, Lavras, 2003.

POZZA, A. A. A. et al. Efeito do silício no controle da cercosporiose em três variedades de cafeeiro. Fitopatologia Brasileira, v. 29, n. 2, p. 185-188, 2004.

PULZ, A. L. et al. Influência de silicato e calcário na nutrição, produtividade e qualidade da batata sob deficiência hídrica. Revista Brasileira de Ciência Solo, v. 32, p. 1651-1659, 2008.

RODRIGUES, F. A. et al. Silicon enhances the accumulation of diterpenoid phytoalexins in rice: a potential mechanism for blast resistance. Phytopathology, v. 94, p. 177-183, 2004.

SANTOS, G. R. et al. Progresso do crestamento gomoso e perdas na cultura da melancia. Horticultura Brasileira, v. 23, n. 2, p. 228-232, 2005.

SANTOS, G. R. et al. Fontes e doses de silício da severidade do crestamento gomoso e produtividade da melancia. Bioscience Journal, v. 26, n. 2, p. 266-272, 2010.

SANTOS, G. R. et al. Effect of silicon sources on rice diseases and yield in the State of Tocantins, Brazil. Acta Scientiarum Agronomy, v. 33, n. 3, p. 451-456, 2011.

SUKNO, S. A. et al. Root infection and systemic colonization of maize by Colletotrichum graminicola. Applied and Environmental Microbiology, v. 74, p. 823-832, 2008.

TANAKA, M. A. S.; FREITAS, J. G.; MEDINA, P. F. Incidência de doenças fúngicas e sanidade de sementes de trigo sob diferentes doses de nitrogênio e aplicação de fungicida. Summa Phytopathologica, v. 34, n. 4, p. 313-317, 2008.

WANG, Y.; STASS, A.; HORS, T. W. Apoplastic binding of aluminum is involved in silicon-induced amelioration of aluminum toxicity in maize. Plant Physiology, v. 136, n. 3, p. 3762-3770, 2004.

ZANETTE, G. F.; NÓBREGA, G. M. A.; MEIRELLES, L. D. P. Morphogenetic characterization of Colletotrichum sublineolum strains, causal agent of anthracnose of sorghum. Tropical Plant Pathology, v. 34, n. 3, p. 146-151, 2009. 